$\begin{array}{ll}\text { Abstracta Iranica } & \begin{array}{l}\text { Abstracta Iranica } \\ \text { Revue bibliographique pour le domaine irano-aryen }\end{array} \\ & \text { Volume } \mathbf{3 4 - 3 5 - 3 6 |} \mathbf{2 0 1 7} \\ \text { Comptes rendus des publications de 201 1-2013 }\end{array}$

\title{
Mehdi Azaiez (sous la direction de) et Sabrina Mervin (avec la collaboration de). Le Coran, nouvelles approches
}

Mathieu Terrier

\section{(2) OpenEdition \\ Journals}

Édition électronique

URL : http://journals.openedition.org/abstractairanica/42391

DOI : 10.4000/abstractairanica.42391

ISSN : 1961-960X

Éditeur :

CNRS (UMR 7528 Mondes iraniens et indiens), Éditions de l'IFRI

Référence électronique

Mathieu Terrier, « Mehdi Azaiez (sous la direction de) et Sabrina Mervin (avec la collaboration de). Le Coran, nouvelles approches », Abstracta Iranica [En ligne], Volume 34-35-36 | 2017, document 6, mis en ligne le 30 juillet 2017, consulté le 26 septembre 2020. URL : http://journals.openedition.org/ abstractairanica/42391 ; DOI : https://doi.org/10.4000/abstractairanica.42391

Ce document a été généré automatiquement le 26 septembre 2020.

Tous droits réservés 


\title{
Mehdi Azaiez (sous la direction de) et Sabrina Mervin (avec la collaboration de). Le Coran, nouvelles approches
}

\author{
Mathieu Terrier
}

\section{RÉFÉRENCE}

Mehdi Azaiez (sous la direction de) et Sabrina Mervin (avec la collaboration de). Le Coran, nouvelles approches. Paris, CNRS Éditions, 2013,339 p. 22,5 cm, $25 €$, ISBN :

978-2-271-07918-3

1 Cet ouvrage collectif a l'ambition de fournir un état des lieux des recherches sur le Coran à un moment-charnière de leur histoire, alors qu'elles sont émancipées de la tradition musulmane et que les hypothèses sur les sources, l'élaboration et les significations du Coran se sont multipliées. Deux types d'approches sont ici présentées : l'un diachronique et "externaliste ", s'intéressant, en amont de la prédication de Muhammad, aux sources du Coran, et en aval de celle-ci, au processus de constitution de la Vulgate ; l'autre synchronique et "internaliste ", étudiant le texte dans son état final selon les méthodes modernes d'analyse littéraire. L'ouvrage se compose de trois parties : l'histoire du texte, la reconstitution de son contexte d'émergence et son analyse littéraire.

Trois approches viennent d'abord remettre en cause l'histoire traditionnelle du Coran. L'approche codicologique de F. Déroche décrit les innovations techniques apparues dans la composition des manuscrits coraniques sous les Omeyyades, mettant en lumière une volonté de contrôle officiel du texte écrit. L'approche philologique de M. A. AmirMoezzi propose d'ouvrir les « archives de l'opposition » shi'ite sur l'histoire du Coran, des sources anciennes longtemps ignorées soutenant que le Coran officiel a subi une 
censure et une falsification. Enfin, l'approche épigraphique de F. Imbert nous fait découvrir le "Coran des pierres ", des graffiti inscrits sur les roches d'Arabie et de Syrie au cours du premier siècle de l'islam, révélant un état du texte encore indépendant du contrôle officiel.

3 La deuxième partie propose différentes interprétations du « contexte d'émergence » du Coran. A. Neuwirth montre que les sourates coraniques les plus anciennes représentent un dialogue avec les Psaumes tandis que les communications médinoises discutent les croyances chrétiennes et juives. C. Gilliot souligne la double influence du manichéisme et du christianisme syrien, jacobite ou nestorien, sur le Coran mecquois, et revient en particulier sur l'expression de "sceau des prophètes ». Ces deux articles prennent le Coran pour un texte de l'Antiquité tardive, empreint de la riche culture religieuse de l'époque. À l'inverse, J. Chabbi soutient « l'indigénisme » du Coran (p. 197) qu'elle tient pour un "document anthropologique " propre à nous renseigner sur son milieu humain d'origine. G. Gobillot, revenant à une approche comparatiste, analyse les versets dits de l'abrogation (nasH) et montre que l'abrogation-substitution concerne non pas le Coran mais l'héritage scripturaire des Gens du Livre, selon une pratique analogue à celle des Homélies pseudo-clémentines.

4 La dernière partie de l'ouvrage propose une approche synchronique et structuraliste. L'article de P. Larcher analyse les variations graphiques dans le texte édité du Coran pour mettre à jour une certaine autonomie de l'écrit par rapport à l'oral. M. Azaiez fait état d'une recherche en cours sur le " contre-discours coranique ", soit la parole des opposants mise en scène dans de nombreux versets. A.-S. Boisliveau étudie l'évolution du discours autoréférentiel du Coran. M. Cuypers, enfin, applique au verset II, 106 sur l'« abrogation "sa méthode d'analyse fondée sur les principes de la rhétorique sémitique, parvenant par une voie différente à une conclusion similaire à celle de G. Gobillot. Une approche qui fait abstraction du contexte d'élaboration du Coran officiel pour considérer celui-ci comme l'état authentique du texte, ce qui est pourtant en question.

5 En conclusion, les nouvelles recherches rassemblées ici développent des perspectives différentes, parfois apparemment incompatibles, en attente d'un paradigme qui les synthétiserait ou d'une épreuve cruciale qui les départagerait.

\section{AUTEURS}

\section{MATHIEU TERRIER}

Paris 